Prepared for the U.S. Department of Energy under Contract DE-AC05-76RL01830

\title{
Feedbacks from Focus Group Meeting on Training and Implementation of Building Energy Codes in China
}

Shui Bin ${ }^{a}$

Lin Haiyan ${ }^{\text {b }}$

Song Bo ${ }^{\mathrm{b}}$

Mark Halverson ${ }^{\text {a }}$

Meredydd Evans $^{a}$

Zhu Xiaojiao ${ }^{\text {b }}$

${ }^{a}$ Pacific Northwest National Laboratory

${ }^{\mathrm{b}}$ China Academy for Building Research

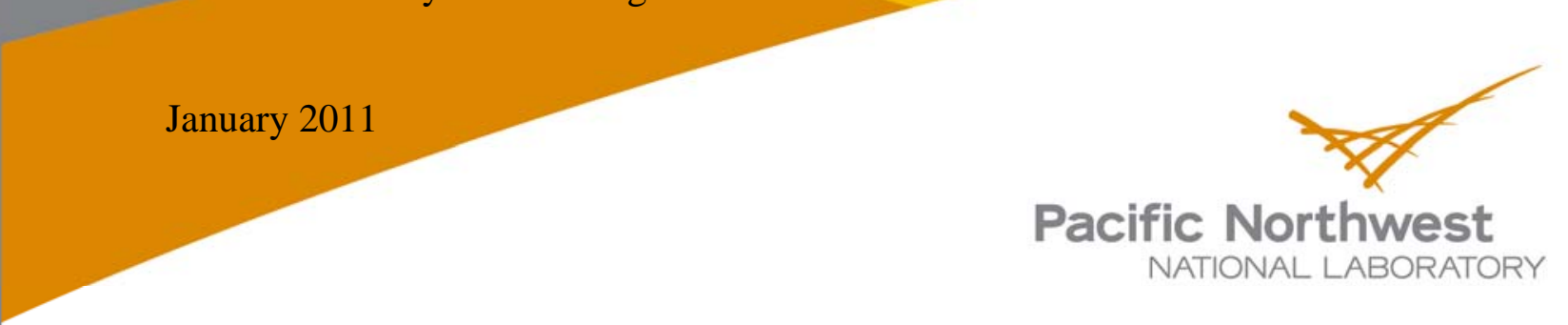




\title{
DISCLAIMER
}

This report was prepared as an account of work sponsored by an agency of the United States Government. Neither the United States Government nor any agency thereof, nor Battelle Memorial Institute, nor any of their employees, makes any warranty, express or implied, or assumes any legal liability or responsibility for the accuracy, completeness, or usefulness of any information, apparatus, product, or process disclosed, or represents that its use would not infringe privately owned rights. Reference herein to any specific commercial product, process, or service by trade name, trademark, manufacturer, or otherwise does not necessarily constitute or imply its endorsement, recommendation, or favoring by the United States Government or any agency thereof, or Battelle Memorial Institute. The views and opinions of authors expressed herein do not necessarily state or reflect those of the United States Government or any agency thereof.

\author{
PACIFIC NORTHWEST NATIONAL LABORATORY \\ operated by \\ BATTELLE \\ for the \\ UNITED STATES DEPARTMENT OF ENERGY \\ under Contract DE-AC05-76RL01830
}

Printed in the United States of America
Available to DOE and DOE contractors from the Office of Scientific and Technical Information,
P.O. Box 62, Oak Ridge, TN 37831-0062;
ph: (865) 576-8401
fax: (865) 576-5728
email: reports@adonis.osti.gov

Available to the public from the National Technical Information Service 5301 Shawnee Rd., Alexandria, VA 22312

ph: (800) 553-NTIS (6847)

email: orders@ntis.gov <http://www.ntis.gov/about/form.aspx>

Online ordering: http://www.ntis.gov 


\title{
Feedbacks from Focus Group Meeting on Training and Implementation of Building Energy Codes in China
}

\author{
Shui Bin ${ }^{\text {a }}$ \\ Lin Haiyan ${ }^{b}$ \\ Song Bo ${ }^{\mathrm{b}}$ \\ Mark Halverson ${ }^{\text {a }}$ \\ Meredydd Evans ${ }^{\text {a }}$ \\ Zhu Xiaojiao ${ }^{\text {b }}$ \\ ${ }^{a}$ Pacific Northwest National Laboratory \\ ${ }^{\mathrm{b}}$ China Academy for Building Research
}

January 2011 


\section{Acknowledgements}

This report owes its existence to the Asia-Pacific Partnership on Clean Development and Climate. We would like to thank Dr. Seung-Eon Lee at the Korean Institute of Construction Technology for his oversight of the APP project under which this report was prepared (BATF 09-52). We would also like to thank Griffin Thompson, Garrett E. Barnicoat, Barth Norman, Nancy Ahson, Kevin Schwartz, and Poliquin Boots from the U.S. Department of State for their leadership and financial support.

We would like to express our gratitude to several other individuals who supported this report in various capacities, including Marylynn Placet, Kay Killingstad, Swieringa Kim, Paulette Land, Kali Wood, Tanya Smith, Anita Jeff, Leon Clark and Tony Janetos at Pacific Northwest National Laboratory. Eric Makela provided the peer review of this report.

This report also owes a great deal to local officials in Ningbo and Changchun who provided tremendous support in arranging focus group meetings. Local participants donated their time (including weekend) to take part in the discussions. They are Zhu Shouzheng, Zheng Chengyan, Bu Fangxiang, Huang Hai, Yin Huanqi, Li Yunchang, Jin Dalong, Pan Yanping, Li Yan, Zhan Yongchang, Ma Da, Yang Hongming, Gu Futian, and Gao Qing in Changchun; and Chen Yongyuan, Pei Jianan, Lin Mi, Cheng Zhenghui, Liu Ming, Hu Chuanwei, Luo Hong, Gong Xuemei, Zhang Zhiying, Zhu Jiping, and Wang Chengdong in Ningbo. 


\section{Contents}

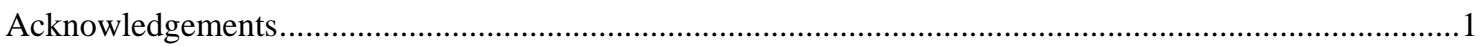

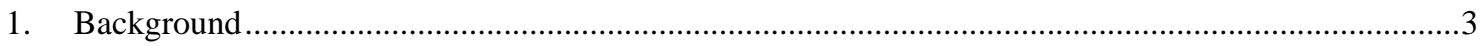

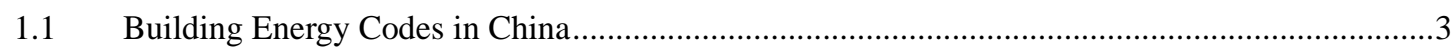

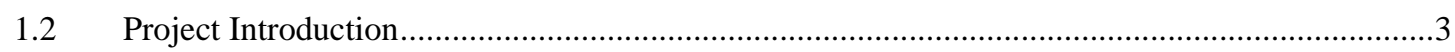

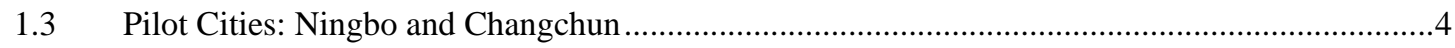

1.4 This Report: Feedback from Focus Group Meetings ..............................................................4

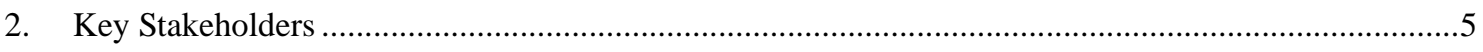

$2.1 \quad$ Relationship between Key Stakeholders ............................................................................5

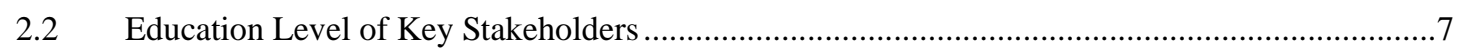

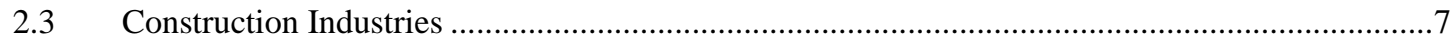

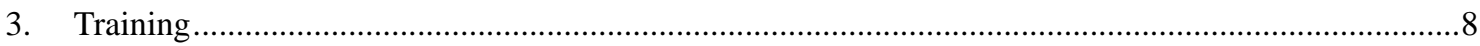

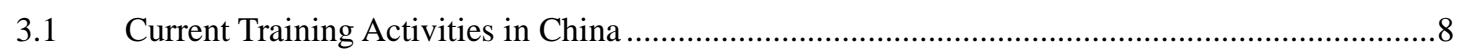

Collected Comments on Web-based Training Activities ..........................................................8

3.3 Collected Comments on Drafted Training Materials .............................................................9

3.4 Some Thoughts about the Development of Training Materials and Training Website................10

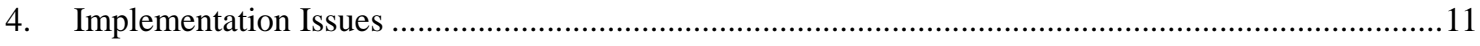

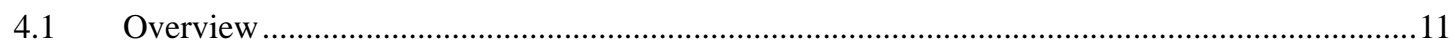

4.1.1 Successful stories: urban in key medium and large cities ................................................11

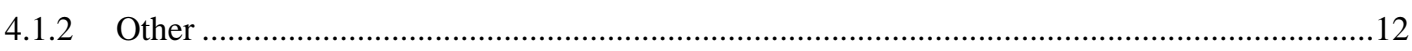

4.2 Major Decision Factors and Common Implementation Difficulties for Key Stakeholders..........12

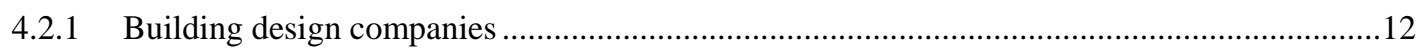

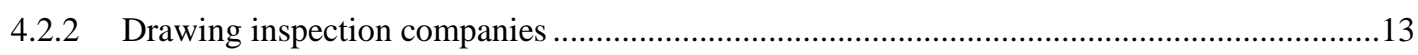

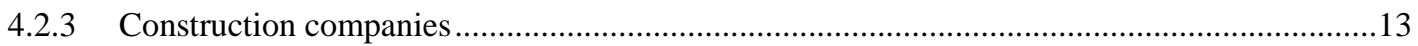

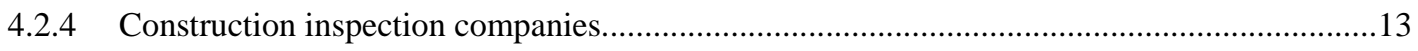

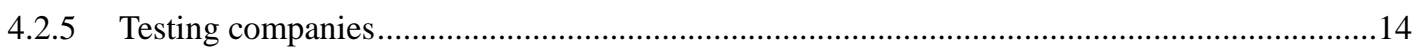

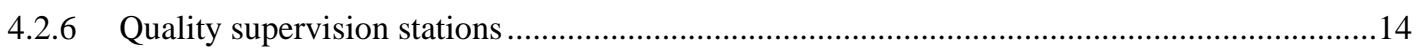

4.3 Some Thoughts on Implementation of Building Energy Codes ............................................14

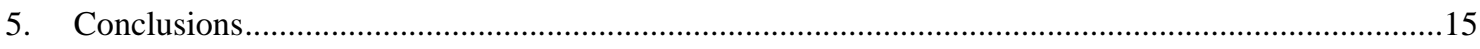

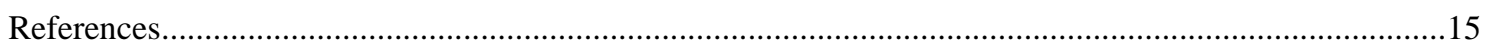




\section{Background}

\subsection{Building Energy Codes in China ${ }^{1}$}

With impressive economic growth in the past three decades, China has emerged as one of the world's largest economies, and top energy consumers and $\mathrm{CO}_{2}$ emitters. According to the International Energy Agency (IEA), China accounted for 14\% of total global building energy use in 2005, with 373 million tons of oil equivalent (Mtoe) that year. From 1995-2005, China's residential energy consumption, the world's largest, accounted for nearly $90 \%$ of its building energy consumption, with a1.1\% annual growth rate. During the same period, the average annual growth rate of its public (including commercial use) building energy use was 7.7\% (IEA 2007).

Since the mid-1980s, when China began its large-scale construction in urban areas, the Chinese government has paid increasing attention to improving building energy efficiency, including the development and implementation of building energy codes. Based on factors such as building energy use, climate and volume of building stocks, China has focused its code development activities more on residential than public buildings, more in the northern China than the south, and more on new rather than existing buildings (Lin 2008).

By now, China has issued a series of national standards and codes to promote building energy efficiency, including three design standards for residential buildings ${ }^{2}$ in different climate zones of China (first published in 1995, 2001, and 2003, respectively), one design standard for public buildings (2005), and the Code for Acceptance of Energy Efficient Building Construction (2007). In addition, China has developed standards for lighting design in buildings (2004). Energy standards covering other building-related issues include: the technical specifications for the energy efficient renovation of existing residential buildings in the heating zones (2001), the technical code for ground source heat pump systems (2005), the technical code for solar water heating systems in civil buildings ${ }^{3}$ (2006), and the standard for energy consumption surveys in civil buildings (2007).

\subsection{Project Introduction}

Under the framework of the Asia-Pacific Partnership on Clean Development and Climate ${ }^{4}$, Pacific Northwest National Laboratory (PNNL) collaborated with China Academy for Building Research (CABR) and Beijing Energy Efficiency Center (BECon) on a project to help the implementation of building energy codes in China. The project, supported by U.S. Department of State, will last from November 2008 to February 2011.

\footnotetext{
${ }^{1}$ This section was slightly edited based on Country Report on Building Energy Codes in China (Shui, et al. 2009)

${ }^{2}$ To date, China has released three national building energy standards for residential buildings. The standards cover different climate zones: the heating zone or severe cold and cold zones (which was first published in 1995 and updated in 2010), the hot-summer-and-cold-winter zone (which was first published in 2001 and updated in 2010), and the hot-summer-and-warm-winter zone (which was first published in 2003).

${ }^{3}$ Civil buildings refer to both residential and public buildings.

${ }^{4} \mathrm{APP}$ is an innovative effort to accelerate the development and deployment of clean energy technologies between Partner Countries, including Australia, Canada, China, India, Japan, Korea, and the United States. "Buildings" is one of eight sectors focused on by this initiative. Please see http://www.asiapacificpartnership.org/english/default.aspx for details.
} 
The goal of this project is to improve the implementation of building energy codes through key project activities such as (1) the development of training materials that are more easily understood by trainees with less technical background and (2) the development of China's first training website devoted to providing free on-line training materials. It is also expected that the project will help improve the understanding of the implementation status of building energy codes in China, such as factors influencing key stakeholders’ decision making.

The targeted building energy codes in this project are (1) design standards of energy efficiency for residential buildings in cold and severe cold regions (1995 and 2010), (2) design standards of energy efficiency for residential buildings in hot-summer-and-cold-winter regions (2001 and 2010), (3) design standards of energy efficiency for public buildings (2003), and (4) the Code for Acceptance of Energy Efficient Building Construction (2007).

The cities of Ningbo, Zhejiang province, and Changchun, Jilin province, were selected as pilot cities for this project.

\subsection{Pilot Cities: Ningbo and Changchun}

Changchun, meaning "Long Spring", is the capital and largest city in Jilin province. Changchun had urban population of 3.6 million in 2007, with a GDP of US\$28.6 billion that year. As the largest automobile manufacturing location in China, Changchun is often described as "China's Detroit." Located in the northeastern part of China, Changchun has a monsoon-influenced, humid and continental climate, with long, cold and dry winter. It is categorized as a severe-cold-and-cold climate zone in Chinese building energy codes.

Ningbo, meaning "Calm Wave”, is a famous port city with a rich culture and history. It is located in the east part of China, about 280 kilometers (or 174 miles) to Shanghai. As the second largest city in Zhejiang province, the urban areas of Ningbo houses 2.2 million people, with a GDP of US\$61.7 billion in 2009, nearly 63.6 percent from exports ${ }^{5}$. Ningbo has monsoon-influenced humid subtropical climate, with four distinct seasons. Ningbo is categorized as the hot-summer-and-cold-winter climate zone in Chinese building energy codes.

\subsection{This Report: Feedback from Focus Group Meetings}

A focus group meeting is a type of qualitative research approach in which a group of participants are gathered to discuss their opinions and perceptions of a specific product, concept, and service. A moderator often coordinates the discussions, with a prepared questionnaire. This approach has been widely used to collect information in marketing and social science studies.

In order to better design the training materials of building energy codes, understand the trainees (or key stakeholders) and implementation issues, a focus group meeting was conducted in each pilot city on August 7 and 11, 2010, respectively. About 25 local participants in total attended these two meetings. These participants were from building design companies/research institutes, drawing

\footnotetext{
${ }^{5}$ http://english.ningbo.gov.cn/col/col55/index.html
} 
inspection companies, construction companies, construction inspection companies, testing companies, and quality supervision stations.

The focus group meetings aimed to gather the following information:

(1) Stakeholder-related information, including their education level, key decision factors, and common difficulties faced by key stakeholders (Section 2);

(2) Training-related information, including the current training approach, participants' comments on proposed on-line training development and the drafted training materials (Section 3); and

(3) The implementation-related information, including the key decision factors affecting decision making of stakeholders, common difficulties they face, and the implementation status in county and small neighboring cities (Section 4)

This report will brief the collected information from the focus group meeting, and present some thoughts on the strategies necessary to improve the development of training materials and implementation (Sections 3 and 4).

\section{Key Stakeholders}

\subsection{Relationship between Key Stakeholders}

China has established a top-down development and implementation system to promote the compliance of building energy codes (see Figure 1).

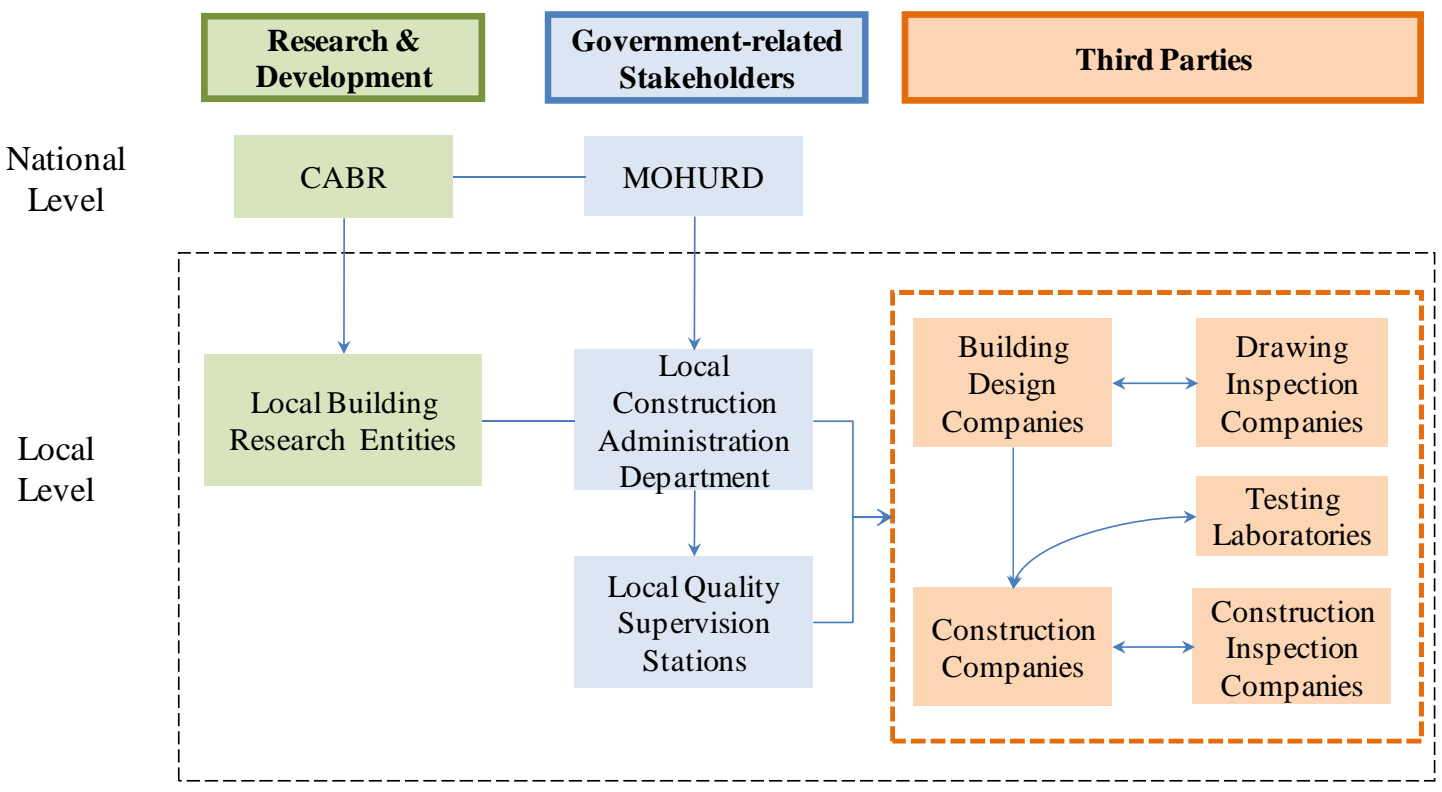

Figure 1 Key Stakeholders in the Implementation of Building Energy Codes in China

At the national level, the Ministry of Housing and Urban-Rural Development (the former Ministry of Construction, or MOHURD) coordinates and supervises the development and implementation of China's national building energy codes. CABR is the chief developer of nearly all of China's national 
building energy codes. On behalf of MOHURD, CABR is responsible for interpreting and maintaining China's building energy codes.

At the local level, local governmental agencies, local building research entities, and an array of third parties interact in the process of building construction and code enforcement.

Local construction administration departments, which report to both the city governments and to the provincial branches of MOHURD, are in charge of day-to-day enforcement activities, such as granting building permits and promoting the enforcement of building energy codes. Some cities can decide if they want to adopt national standards, or develop their own.

Local quality supervision stations are assessed and certified by the provincial administrative departments. The stations, which act as governmental monitoring agencies, are in charge of construction quality control and supervising work quality of third parties. Their activities include inspecting the building during key construction phrases and collecting, reviewing, and approving documents related to construction and code compliance.

Local building research entities, some of which are related to CABR, provide strong technical support not only to local construction administration departments, but also to other key stakeholders. For example, some local building research institutions can provide building design service hired by a developer.

Building design companies, drawing inspection companies, construction companies, construction inspection companies, and testing companies and labs are third parties in the implementation process. They are hired by a developer through a bidding process and work for the developer to construct a building that complies with adopted building codes.

- Building design companies shall strictly follow requirements of the design standard for energy efficiency during the design stage of a building.

- Drawing inspection companies, consisting of senior building designers previously hired or retired from building research entities or building design companies, shall verify the building drawing to be code-compliant. Drawing inspection companies are independent from building design companies.

- Construction companies shall construct a building by following approved building drawing design and Code for Acceptance of Energy Efficient Building Construction (2007).

o During our site visit to a construction site in 2009, we found that the construction company followed a strict quality control process to make sure construction complied with code requirements.

- Construction inspection companies shall inspect and verify the construction to be compliance to both verified drawing and Code for Acceptance of Energy Efficient Building Construction (2007). Construction inspection companies are independent from construction companies. The companies send their staff to conduct on-site inspection through the construction phrases.

- Testing companies and labs shall help test building materials sent by construction companies and manufacturers, according to Code for Acceptance of Energy Efficient Building 
Construction (2007).

\subsection{Education Level of Key Stakeholders}

The education level of construction industry varies from middle school and below to undergraduate and above. For example, building designers, drawing inspectors, construction inspectors, and quality supervisors often have bachelor degrees. Nearly all of drawing inspectors were senior engineers from building design companies and research institutes, with many years of working experience.

Construction companies' employees include both managers and construction workers. Managers often have at least a college education, while construction workers often have education degrees at the middle school level and below. Testing engineers have college degrees (see Table 1).

Since 1994, China has formed a comprehensive title examination system for construction industry employees. Through the examination and assessment, construction industry employees get the corresponding titles or licensing (see Table 1). A certificate remains valid for about 2 to 3 years. When a certificate is about to be expired, the holder needs to go through registration procedures at the designated agency and fulfill requirements of continuing education.

Table 1 Average Education Level and Title Exams for Certificates by Stakeholders

\begin{tabular}{|c|c|c|c|}
\hline & $\begin{array}{c}\text { Affiliated } \\
\text { organizations }\end{array}$ & $\begin{array}{c}\text { Average } \\
\text { education level }\end{array}$ & $\begin{array}{l}\text { Relevant title exams } \\
\text { for certificates }\end{array}$ \\
\hline Building designers & $\begin{array}{l}\text { Building design } \\
\text { companies, } \\
\text { building research } \\
\text { entities }\end{array}$ & undergraduate and above & \multirow{2}{*}{$\begin{array}{l}\text { registered architect, certified } \\
\text { structural engineer, certified } \\
\text { electrical engineer, certified } \\
\text { equipment engineer, quality } \\
\text { inspector, geotechnical engineer, } \\
\text { interior designers, certified cost } \\
\text { engineer, cost engineer, etc }\end{array}$} \\
\hline Drawing inspectors & $\begin{array}{l}\text { Drawing } \\
\text { inspection } \\
\text { companies }\end{array}$ & $\begin{array}{l}\text { undergraduate and above } \\
\text { (with many years of } \\
\text { working experiences) }\end{array}$ & \\
\hline $\begin{array}{l}\text { Construction } \\
\text { managers }\end{array}$ & \multirow[t]{2}{*}{$\begin{array}{l}\text { Construction } \\
\text { companies }\end{array}$} & college & \multirow{3}{*}{$\begin{array}{l}\text { constructor, certified cost engineer, } \\
\text { cost engineer, construction } \\
\text { workers, technician, security } \\
\text { engineer, quality inspector, etc }\end{array}$} \\
\hline Construction workers & & middle school and below & \\
\hline $\begin{array}{l}\text { Construction } \\
\text { inspectors }\end{array}$ & $\begin{array}{l}\text { Construction } \\
\text { inspection } \\
\text { companies } \\
\end{array}$ & undergraduate & \\
\hline Testing engineers & $\begin{array}{l}\text { Testing } \\
\text { companies or labs }\end{array}$ & college & certified testing engineer \\
\hline Quality supervisors & $\begin{array}{l}\text { Quality } \\
\text { supervision } \\
\text { stations }\end{array}$ & undergraduate & supervision engineer \\
\hline
\end{tabular}

\subsection{Construction Industries}

China's construction industry has formed a relatively complete system, including sub-industries such as building design companies, drawing inspection companies, construction companies, construction inspection companies, testing stations, and quality supervision stations. It is estimated that thousands of employees (not including construction workers) in each pilot city directly work for construction industries.

Quality supervision stations, which are semi-governmental agencies and paid for by the city government, are not officially part of any governmental organization. 
The "third party" component in the implementation of building energy codes includes the following companies: construction, building design, construction inspection, drawing inspection, and testing (see Fig. 1). There are more than 100 construction companies, about a hundred of building design companies, dozens of construction inspection companies, less than ten drawing inspection (seven in Changchun and five in Ningbo), and less than five testing companies and labs (four in Ningbo) in each pilot city.

\section{Training}

\subsection{Current Training Activities in China}

Training is a component in China's current efforts to promote the compliance and implementation of building energy codes. The most common training form is training seminars. The target trainees for design standards of energy efficiency for residential and public buildings include engineers from building design companies and drawing inspection companies. The target trainees for Code for Acceptance of Energy Efficient Building Construction include construction managers, engineers from construction inspection companies, testing companies and labs, and quality supervision stations.

CABR, the national developer of most building energy codes in China, often kicks off a first national training seminar when a new or updated national building energy code is officially issued.

Local (provincial or city) construction administrative commissions provide or organize training seminars at local or sectoral level. Some of these training seminars are free to trainees while others involve training fee. Invited trainers are well-known experts and scholars in the field.

Construction companies often organize free training activities (such as a training class or on-site training) for their workers. Trainers are experts or peers with advanced knowledge about the training subject(s).

\subsection{Collected Comments on Web-based Training Activities}

Web-based training activities related to building energy codes have been used by some countries, including the United States.. China has yet to establish a website that is devoted to providing comprehensive on-line training on building energy codes. As a country with the largest on-line population, China has great potential to employ an on-line training approach to promote building energy efficiency. A key project activity is to develop China's first website dedicated to web-based training activities.

At the focus group meetings, participants expressed their opinions on the perspective of developing an on-line training website. Generally speaking, participants viewed web-based training activities very positively. They agreed that the development of web-based training activities is a good approach worthy of trying. Some participants pointed out that web-based training could provide greater flexibility that conventional training seminars do not provide. For example, a trainee could choose a training time and training materials, and set up his/her own pace of training. Focus group participants also agreed that providing free training would help attract more participants. 
Some participants were concerned that the on-line training activities may not be as effective as training seminars. They argued that on-line training may not provide tailored answers for questions raised by trainees, which was a common case at training seminars. In addition, without incentives and mandatory mechanisms, trainees may be less motivated to take or engage in on-line training activities.

\subsection{Collected Comments on Drafted Training Materials}

A training seminar of building energy codes in China is often tightly scheduled. The training materials for such a seminar are therefore compact, with focus on the explanation of key provisions of building energy codes, and with assumption that the participants would be equipped with good technical understanding of prior building energy codes.

A web-based training may be different from a training seminar in several ways:

(1) A web-based trainee, no matter their technical and education level, may have less access to a training seminar due to reasons such as: financial constraints, time availability, or lack of internet access.

(2) A web-based trainee may be interested in reviewing the training materials he/she obtained at a training seminar at his/her own pace;

(3) A web-based trainee may be interested in choosing a different training subject than the area in which they would be trained;

(4) Web-based training materials should be more self-explanatory, considering (a) the variety of technical and educational levels of possible participants and (b) there are no direct interactive question and answer sessions that would be part of live training seminars.

The design of the web-based training materials needs to be self-explanatory and informative, with simple and clear explanation, and interactive components if possible. Using visual aids (such as figures, tables, pictures, and color fonts) would help encourage reading and understanding.

In the focus group meetings, we presented the developed training materials (draft) for participants' comments. The developed training materials included:

(1) Background information slides on China energy status

(2) Training presentation slides on design standards of energy efficiency for public buildings;

(3) Training presentation slides on design standards of energy efficiency for residential buildings in the cold-and-severe-cold climate zone;

(4) Training presentation slides on design standards of energy efficiency for residential buildings in the hot-summer-and-cold-winter regions;

(5) Training presentation slides on Code for Acceptance of Energy Efficient Building Construction; and

Participants of focus group commented that the developed training materials were comprehensive and concrete, meeting the needs of building energy efficiency training. They also provided suggestions on the improvements of contents in the following areas: 
- Introduction of energy-saving building materials Although many energy-saving building materials and technologies are available on the market, there is lack of information to introduce the differences among building materials as well as technologies. Building designers often find themselves having difficulties deciding which building materials and construction technologies should be selected. For example, they are not sure the performance of the building materials.

Some participants suggested that it would be very helpful for trainees to obtain the corresponding knowledge through training materials. They are interested in such information from the United States and other developing countries with case studies.

- Introduction of building technology There is lack of information on specific building technology. Participants suggested there is a need for the development of best practice, case studies, and construction atlas which specifies the construction procedures with instructional notes, pictures and figures.

- Energy-saving calculation software Energy-saving calculation software has been widely used in building design companies for calculation of building energy saving. Some participants from design companies suggested that an introduction of its usage and applications in the training materials would be helpful for designers to better understand the software.

\subsection{Some Thoughts about the Development of Training Materials and Training Website}

In order to improve the current training materials, the next steps will add information about (1) the introduction of energy-saving of building materials, (2) building technologies, and (3) the related calculation software, especially from newly updated design codes of energy efficiency for residential buildings in the cold-and-severe-code zones and the hot-summer-and-cold-winter zones.

In addition, training materials on China energy status and building energy policies will be updated and included in the developed website. These training materials, which are often absent in the current training seminars, will help provide necessary background information for trainees to understand the role of the compliance of building energy codes in the big picture.

A section of questions and answers will be added on the training website. This section will include common questions raised by trainees during training seminars or personal communications with key building developers. This will help ease the participants' concerns about the lack of tailored answers for common questions from web-based training.

The future training activities, with additional financial support, may work on other important training activities, such as providing webcast and online video-taped training, developing training materials for building developers, adding interactive features in web-based training, providing regional or local experiences of building energy efficiency, and collecting the best case studies. In addition, development of incentive approach for promoting training (such as a training certificate to be used for career advancement) could be another interesting future project topic. 


\section{Implementation Issues}

This section contains an overview of the implementation status of building energy codes in China, including a brief of the implementation status in urban areas, the neighboring small cities and counties, as well as rural areas (Section 4.1).

Understanding major factors affecting decision making of key stakeholders, and their difficulties in the compliance and enforcement of building energy codes is one of first steps to develop sound strategies to improve the compliance and enforcement. A key component of focus group meetings was to collect information on this topic (Section 4.2).

Some thoughts on the improvement of compliance and enforcement are presented in this section as well (Section 4.3).

\subsection{Overview ${ }^{6}$}

Enforcement of building energy standards in China has historically been problematic. The enforcement is much stronger in major medium and large cities than smaller cities and rural towns as well as in the north and in developed regions compared to the south and less economic developed regions.

\subsubsection{Successful stories: urban in key medium and large cities}

Since 2005, MOHURD has significantly enhanced the enforcement efforts related to building energy codes. Since then, certified third-party companies were tasked with deeper and closer involvement of the compliance and enforcement processes. Without the approval of a certified drawing inspection company, the local construction administrative department cannot allow construction to start. Without the approval of a construction inspection company, the new building cannot be sold or used.

MOHURD has launched an annual national inspection survey of building energy efficiency in key Chinese cities the same year. Some provinces (such as Zhejiang) and cities (such as Changchun and Ningbo) have correspondingly conducted their annual surveys in order to better prepare the national survey.

The release of the Code for Acceptance of Energy Efficient Building Construction, issued by MOHURD in 2007, is a milestone not only of governmental regulatory efforts to implement building energy codes, but also technical code development in China.

Based on the current official survey conducted by Chinese, the drawing and construction compliance rate in key medium and large Chinese cities are reaching 95 and 80 percent, respectively (Lin 2009). Our discussion with officials from local construction administrative commission in Ningbo and

\footnotetext{
${ }^{6}$ This section was slightly edited based on Section 1 Introduction and Background from Country Report on Building Energy Codes in China (Shui, et al. 2009)
} 
Changchun confirmed that the compliance rate in drawing and construction in the urban areas are above 98 and 90 percent, respectively.

\subsubsection{Other}

The urban areas in Changchun and Ningbo have established a rather comprehensive institution to promote the compliance of building energy codes, with an array of building design companies, drawing review companies, construction companies, construction inspection companies, testing companies, and quality supervision stations. Small cities and towns, which are close to the urban areas of Changchun and Ningbo, are said to have similar implementation status, according to discussion with participants of focus group meetings and separate chats with local officials and CABR experts. The main reason is that the neighboring small cities and counties have the same or very similar construction institutions (including third-party companies) as urban areas.

For small townships and rural areas, which are distant from urban areas of medium and large cities, the implementation of building energy codes is less satisfactory. Most of these areas do not have local construction departments or quality supervision stations. They have not been targeted intensively by the government as areas of implementation for building energy codes. However, new buildings supported by governmental or international funding should follow the same compliance and enforcement procedures as in the urban areas. We learnt that the Chinese government has started to promote the implementation of building energy codes in the rural areas since late 2009.

\subsection{Major Decision Factors and Common Implementation Difficulties for Key Stakeholders}

\subsubsection{Building design companies}

Key decision factors The objectives of building design companies are to design buildings in accordance with a series of design codes (including the design codes for building energy efficiency), and to meet developer requirements.

Building design companies pay heavy attention on the following issues: (1) understanding and integrating the requirements of design standards of building energy efficiency into building design; (2) meeting the cost and energy performance requirements set by a hiring developer; (3) utilizing new materials and technology in the building design to meet or exceed the building energy efficiency requirements, and (4) having flexibility in applying design standards.

Building design companies take similar factors into consideration when designing new buildings in urban and suburban areas. For designing new buildings in small townships and rural areas, building design companies may focus on the first two factors listed above.

Identified difficulties When the shape of a new building is not a regular one defined by the design code of energy efficiency for residential and public buildings, building designers often find themselves absorbed by difficult energy-saving computations required by the design standards.

In addition, many building designers have little knowledge about new building materials and technologies (There is not much relevant information available on the market). They often find 
themselves having difficulties choosing which type of building material is more suitable to improving the building energy efficiency for a designed construction project.

\subsubsection{Drawing inspection companies}

Key decision factors The major duty of drawing inspection companies is to examine whether design drawings are in line with a series of national policies and regulations related to buildings, as well as the mandatory requirements of building standards and codes, such as fire safety and energy efficiency requirements.

Most drawing inspection companies are located in urban areas. They use the same inspection criteria to review building designs regardless of the proposed building location.

Identified difficulties Usually, drawing reviewers can strictly implement the energy efficiency codes. There are few difficulties identified by participants at focus group meetings.

\subsubsection{Construction companies}

Key decision factors The objectives of construction companies are to follow building design, and comply with construction techniques and requirements of building materials provided by the acceptance code.

Construction companies often address the following factors: (1) making sure the whole construction process meets the code acceptance requirements, (2) project cost control, (3) durability of building materials and meeting engineering requirements, and (4) construction quality to meet the requirements of both codes and developers. Construction companies working for new buildings in small townships and rural areas pay more attention to (1) the cost of the project and (2) the durability of building materials.

Identified difficulties Common difficulties for construction companies include the following: (1) lack of knowledge in identifying the quality of building materials, such as materials' durability and strength, (2) conflicted interests between high priced energy-efficient building materials and cheaper, but less efficient materials, and (3) a lack of knowledge of building techniques.

\subsubsection{Construction inspection companies}

Key decision factors Construction inspection companies are often hired by a developer to supervise the construction quality, monitor the construction process, and control construction costs. The main factors addressed by construction inspection companies include achieving the following goals (1) a construction process that meets the requirements of acceptance codes, (2) a construction project that is completed on time, and (3) a project that is within the budget.

Identified difficulties Construction inspectors complain that there is lack of standardized specification for construction technique. They have difficulties identifying the quality of building materials. In addition, a construction project which meets design standards of energy efficiency for residential and public buildings often incurs costs higher than the budget. 


\subsubsection{Testing companies}

Key decision factors Testing companies help examine the equipment performance and quality of building materials used in a construction project. Test companies are often located in urban areas or neighboring areas.

Key decision factors include: (1) whether the performance parameters of equipments and building materials meet the requirements as defined by the acceptance codes; and (2) whether a construction project meets the requirements set by the acceptance codes.

Identified difficulties Testing engineers find that many developers, construction companies, and equipment and material supply companies do not have a thorough understanding of the acceptance codes. Selected samples for inspection often do not meet the requirements. In addition, the current testing capabilities of some testing companies are not comprehensive enough to meet the testing requirements.

\subsubsection{Quality supervision stations}

Key decision factors A quality supervision station, managed by its local construction administrative department, makes sure the whole construction process of a construction project would comply with quality control procedures and requirements (including the compliance of design standards and acceptance codes).

Identified difficulties Several participants at focus group meetings, who were from quality supervision stations, pointed out that their staff needed to be better trained to understand and apply the acceptance code.

\subsection{Some Thoughts on Implementation of Building Energy Codes}

Based on the implementation information collected from focus group meetings, it is clear that there is a lack of (1) information of energy-saving building materials and building techniques, (2) knowledge of software application, (3) understanding of building energy codes, especially the acceptance code, and (4) the integration of life-cycle benefit-cost analysis into budgeting. These identified factors have become major hurdles to better compliance of building energy code laws.

These findings, collected from the discussions of implementation issues, are quite consistent with feedback from the discussions of training needs. It confirms that the improvement of training quality shall be considered as a very critical effort to promote building energy codes in China.

Participants also shared their thoughts on the improvement of building energy codes in rural areas, such as simplification of construction technology, standardization of energy-saving building materials, education of farmers about the benefits of building energy efficiency and a cost benefit analysis of an energy-efficient building project. 


\section{Conclusions}

A focus group meeting is a very effective quality research approach to collect information on a specific project. Through focus group meetings at both Changchun and Ningbo in August 2010, the project team gained a more complete understandings of key stakeholders (such as their education level), their training needs and expectations, key factors influencing their decision making, and incurred implementation difficulties. In addition, the meeting helped the project team (especially PNNL) improve its understanding of the implementation status of building energy codes in other regions (such as small cities and counties neighboring to urban areas, small townships and rural areas distant from urban areas).

The collected feedbacks will serve as important input not only for better design of training materials and the development of an on-line training website, but also for development of follow-up projects to promote building energy codes in China.

\section{References}

1. IEA. 2007. Energy Balances of Non-OECD Countries (2007 edition).

2. Lin, Haiyan. 2008. A Brief Introduction to the Chinese Design Standards for Energy Efficiency in Residential Buildings. Beijing: China Academy of Building Research

3. Shui B, M Evans, H Lin, W Jiang, B Liu, B Song, and S Somasundaram. 2009. Country Report on Building Energy Codes in China. PNNL-17909, Pacific Northwest National Laboratory, Richland, WA. 